\title{
Recycled Liquid Cattle Manure as a Sole Fertilizer Source for Growing Container Nursery Stock in a Closed System
}

\author{
Mohammed Z. Alam ${ }^{1}$ \\ Agriculture and Agri-Food Canada, Crop Science, 32 Main Street, Kentville, \\ Nova Scotia, Canada B4N 1J5

\section{Calvin Chong} \\ Department of Plant Agriculture, University of Guelph, Guelph, Ontario, \\ Canada N1G 2 WI
}

Additional index words. nutrient recirculation, liquid manure recycling, container culture, ornamentals, deciduous woody species

There is increasing environmental concerns about irrigation runoff, leachates, and other effluents from farms, composting sites, and other operations (Hong et al., 2009; LeaCox et al., 2004; Yeager et al., 1993). Waste effluents may cause surface and groundwater contamination (Million et al., 2007; Owen et al., 2008). Effluents are often rich in certain nutrients and can potentially be recycled for fertilizing plants (Alam and Chong, 2006; Owen et al., 2008; Qian et al., 2005).

Wastewaters from diverse sources, including municipal effluent (Beltrao et al., 1999; Kızıloglu et al., 2007; Manios et al., 2006; Qian et al., 2005), compost leachates (Shrive et al., 1994; Welke, 2004), and liquid byproduct from anaerobic digestion (Little and Grant, 2002; Michitsch et al., 2008) have been used in various crop production systems.

In North America, captured irrigation runoff has long ago been advocated for reuse in the fertigation of container nursery crops (Harrison, 1976; Skimina, 1986) and is increasingly being researched/used today (Beeson et al., 2004; Moore et al., 2008; Mosley and Fleming, 2009). However, it is labor-intensive to recycle wastewater and difficult to achieve a proper nutrient balance without proper equipment.

With the aid of an experimental-sized, computer-controlled multifertigation injector system, initially patented for use in growing greenhouse vegetable crops (Climate Control Systems, 2000; Papadopoulos and Liburdi, 1989), the ornamental nursery research pro-

Received for publication 1 Oct. 2009. Accepted for publication 30 Oct. 2009.

Financial and infrastructure support was provided by the Ontario Ministry of Agriculture, Food and Rural Affairs (OMAFRA) and by the OMAFRA Tier 1 Research Support Program.

We thank Eric Labatte for design and technical support of the fertigation system.

${ }^{1}$ To whom reprint requests should be addressed; e-mail zalam@uoguelph.ca. gram at the University of Guelph began to recycle container leachates for growing nursery plants in a closed system (Chong et al., 2004; Purvis et al., 2000). In this context, Chong et al. (2008) reported use of mushroom farm and anaerobic digestion wastewater as supplementary fertilizer sources for container culture of selected nursery plants. The aim of this related investigation was to ascertain if liquid cattle manure (LCM) could be used as the sole nutrient source under similar cultural conditions.

The computer-controlled multifertigation injector was described by Purvis et al. (1998). The system basically consisted of 10 electrically driven, individually controlled dosimetric injection pumps, various electrical conductivity (EC), $\mathrm{pH}$, and flow sensors and two nutrient blending tubes connected in series. To fertigate, the computer can be programmed to deliver a set amount of any type of nutrient (individual, mixed, or acid) from its own individual stock container, i.e., a total of 10 types simultaneously, one per dosimetric pump. A series of $2 \%$ sloped crisscrossing, interconnecting aluminium troughs $(25 \mathrm{~cm}$ wide $\times 3 \mathrm{~cm}$ deep $\times 5 \mathrm{~m})$ directed leachates from containers into three large $(1300 \mathrm{~L})$ in-ground storage mixing tanks, each also equipped with its own EC sensor, and continuously aerated. The injector and mixing tanks were connected to a computer through an interface panel. This fourth-generation configuration of the system allowed recirculation of up to three different nutrient solutions, fresh water, or both; automatic or manual recharging of the solutions; and treatment randomization (Chong et al., 2008).

On 12 June 2007, plug-rooted liners of cotoneaster (Cotoneaster dammeri C.K. Schneid. 'Coral Beauty'), silverleaf dogwood (Cornus alba L. 'Argenteo-marginata'), and forsythia (Forsythia xintermedia Zab. 'Spring Glory') were potted in \#2 containers ( $6 \mathrm{~L} ; 21 \mathrm{~cm}$ diameter $\times 21 \mathrm{~cm}$ deep) filled with a growing medium consisting by vol- ume of $65 \%$ pine bark, $25 \%$ peatmoss, and $10 \%$ compost [Grow-Bark (Ontario) Ltd., Milton, Ontario, Canada]. On 21 June, plants were placed $45 \mathrm{~cm}$ apart on the aluminum troughs and grown under four separate fertilizer treatment strategies: 1) control fertilizer solution based on a nutrient formula described in Table 1 with a targeted EC of $2.0 \mathrm{dS} \cdot \mathrm{m}^{-1}$ delivered and recirculated through the computerized injector; 2) recirculated, unamended liquid cattle manure [uLCM; raw liquid from an on-site collection tank at the dairy cattle barn, Elora Research Station, University of Guelph, Ontario, Canada, diluted fourfold with tap water to reduce (adjust) its EC to a value of $2.0 \mathrm{dS} \cdot \mathrm{m}^{-1}$ (chemical composition shown in Table 1)]; 3) recirculated, amended liquid cattle manure [aLCM; fortified with $50 \mathrm{mg} \cdot \mathrm{L}^{-1}$ of $\mathrm{NO}_{3}-\mathrm{N}$ twice (at start and in mid-July), $\mathrm{EC}=2.0 \mathrm{dS} \cdot \mathrm{m}^{-1}$; Table $1]$; and 4) Nutricote $18-6-8$ (18N-6P-8K) T100 controlled-release fertilizer (CRF) with micronutrients (Plants Products Co. Ltd., Brampton, Ontario, Canada) topdressed at a rate of $4.32 \mathrm{~g}$ nitrogen per container as recommended by the manufacturer; nutrients were not recycled. The fertigation solutions in Treatments 1 to 3 as well as water only to Treatment 4 were dispensed by the injector through drip emitters at a rate of $1 \mathrm{~L}$ per container per day throughout the experiment [12 June (start) to 31 Aug. (harvest)]. The experiment was laid out in a split-plot design with the four fertilizer treatments as main plots and the three species as subplots. There were four main plot replications and three plants of each species per subplot unit.

The control fertilizer solution (Treatment 1, Table 1) was formulated by the computer from the following individual nutrient stock and concentration (bracket): $\mathrm{Ca}\left(\mathrm{NO}_{3}\right)_{2} \cdot 4 \mathrm{H}_{2} \mathrm{O}$ $\left(200 \mathrm{~g} \cdot \mathrm{L}^{-1}\right), \mathrm{KH}_{2} \mathrm{PO}_{4}\left(150 \mathrm{~g} \cdot \mathrm{L}^{-1}\right), \mathrm{KNO}_{3}(150$ g. $\left.\mathrm{L}^{-1}\right), \mathrm{K}_{2} \mathrm{SO}_{4}\left(100 \mathrm{~g} \cdot \mathrm{L}^{-1}\right), \mathrm{MgSO}_{4} \cdot 7 \mathrm{H}_{2} \mathrm{O}$ $\left(150 \mathrm{~g} \cdot \mathrm{L}^{-1}\right), \mathrm{Mg}(\mathrm{NO} 3)_{2} \cdot 6 \mathrm{H}_{2} \mathrm{O}\left(150 \mathrm{~g} \cdot \mathrm{L}^{-1}\right)$, $\mathrm{NH}_{4} \mathrm{NO}_{3}\left(200 \mathrm{~g} \cdot \mathrm{L}^{-1}\right)$, iron chelate (ethylene diamine tetra-acetic acid $\left.13.2 \%, 5 \mathrm{~g} \cdot \mathrm{L}^{-1}\right)$, and micronutrient mixture (manganese $24 \%$, zinc $35 \%$, boron $15 \%$ copper $25 \%$, and molybdenum $46 \% ; 1.5 \mathrm{~g} \cdot \mathrm{L}^{-1}$ ).

Samples of the dispensed control solution were collected at the emitter at the start and at 15-d intervals and analyzed for $\mathrm{pH}, \mathrm{EC}$, and the 15 nutrients shown in Table 1. The laboratory-based values were programmed into the computer to facilitate maintenance of target values. Solutions in the LCM tanks were recharged manually at weekly intervals (i.e., when storage tank volumes were depleted $300 \mathrm{~L}$ or less and EC reduced 1.5 $\mathrm{dS} \cdot \mathrm{m}^{-1}$ or less). The recharge procedure was facilitated using a predictive equation modified from Gils et al. (2005): $Y=(V i \times E C i) \times$ $(V i-V d) /[(V r \times E C d)+(V i-V r)] \times E C r$, where $\mathrm{Y}=$ top-up volume of raw LCM; Vi = initial tank volume $(1200 \mathrm{~L}) ; \mathrm{ECi}=$ initial EC of $4 \times$ diluted LCM; Vd $=$ depleted volume; $\mathrm{ECd}=\mathrm{EC}$ of depleted volume; and $\mathrm{ECr}=\mathrm{EC}$ of the raw LCM.

On 31 Aug. (harvest), samples of fully matured leaves were collected from plants of each subplot, dried at $60{ }^{\circ} \mathrm{C}$ for one week, 
weighed, ground, and analyzed for nitrogen, phosphorus, potassium, calcium, magnesium, iron, manganese, zinc, copper, and boron (Agri-Food Laboratories, Guelph, Ontario, Canada). The shoots (stems and remaining leaves) were removed at substrate level, dried (also at $60{ }^{\circ} \mathrm{C}$ for 1 week), and weighed. Dry weight of the leaf samples were added to the final dry weight of the shoot. Roots were also washed under tap water on a 1-cm sieve, dried at $60{ }^{\circ} \mathrm{C}$ for 1 week, and weighed. Data for plant responses were subjected to analysis of variance using SAS GLM (SAS Institute, Inc., Cary, NC). Means were separated by the least significant difference test.

The harvested shoot dry weights by species shown in Figure 1, in response to the four fertilizer strategies, were: cotoneaster, similar in all four treatments; forsythia, highest with unamended LCM; and dogwood, higher in both unamended and $\mathrm{NO}_{3}$-amended $\mathrm{LCM}$ compared with the control and CRF treatments. Corresponding root dry weight responses for both LCM solutions (Fig. 1) were similar to the control solution (cotoneaster and forsythia) or better than the control (dogwood) and, generally, CRF (all species).

In related studies, container leachates (Chong et al., 2004; Purvis et al., 2000), mushroom farm wastewater (raw $\mathrm{EC}=5.3$ $\mathrm{dS} \cdot \mathrm{m}^{-1}$; diluted $\left.10 \times\right)$, and liquid anaerobic digestate $\left(\right.$ raw EC $=18.9 \mathrm{dS} \cdot \mathrm{m}^{-1}$; diluted $\left.20 \times\right)$ (Chong et al., 2008) were recirculated while each of these sources was fortified to targeted nutrient levels by the computerized fertigator. The important and unique contribution of the present article is that LCM was the only source of nutrients. To our knowledge, this is

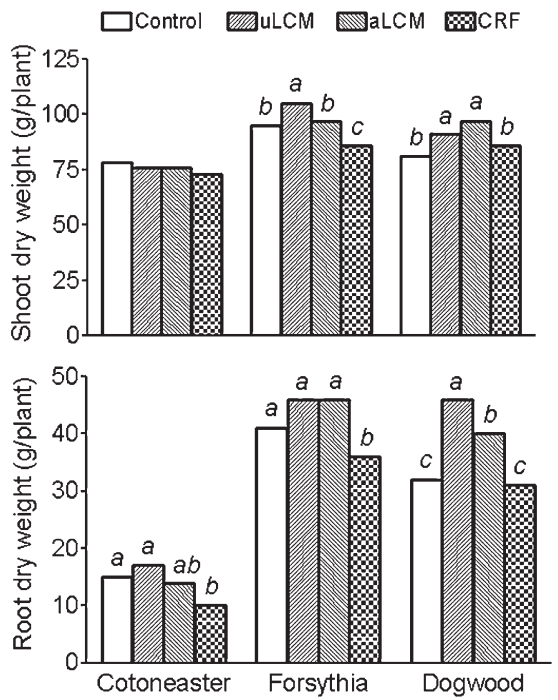

Fig. 1. Shoot and root dry weights of three container-grown species (cotoneaster, forsythia, and dogwood) in response to four fertilizer treatment strategies [control nutrient solution; $4 \times$ diluted and unamended liquid cattle manure (uLCM); diluted, $50 \mathrm{mg} \cdot \mathrm{L}^{-1}$ $\mathrm{NO}_{3}$-amended liquid cattle manure (aLCM); and controlled-release fertilizer (CRF)]. Means within species accompanied by common letters are not significantly different at $P \leq 0.05$ by least significant difference test. 
the first time a liquid manure has been successfully recirculated as a complete fertilizer source. Although the present results are limited to container culture of three woody deciduous ornamental shrubs in a closed recirculating growing system and one source of liquid cattle manure, this advance opens possibilities for testing of other plant species and liquid manures.

When wastewaters are used in plant culture, high salt levels and nutrient variability and imbalances can be hazardous to plants (Beeson et al., 2004; Owen et al., 2008; Shrive et al., 1994; Wang et al., 2007). Similar to many types of liquid wastes reviewed by Alam and Chong (2006), the raw LCM contained salt levels that were excessive $\left(\mathrm{EC}=6.8 \mathrm{dS} \cdot \mathrm{m}^{-1}\right)$ attributable primarily to elevated concentrations of $\mathrm{NH}_{4}-\mathrm{N}$, which comprised $94 \%$ of the nitrogen and, to a lesser extent, excess potassium, calcium, magnesium, $\mathrm{SO}_{4}$, chlorine, and sodium (Table 1). In the control recirculating solution, the actual dispensed values of individual dispensed nutrients did not always match targeted values (Table 1). This observation has been previously reported and seems to be primarily associated with inherent discrepancies in the computer's algorithms relative to different grades of fertilizers (Climate Control Systems, 2000; Papadopoulos and Liburdi, 1989; Purvis et al., 2000).

Before use, chemical analyses of the LCM were conducted to determine its fertilizer properties and composition to devise a strategy for its use in the closed system. Based in part on these data, and also on our prior experience described previously, an initial $4 \times$ dilution of the raw LCM was chosen for use (Table 1) because 1) it retained as much as possible of the $\mathrm{NH}_{4}-\mathrm{N}$, phosphorus, potassium, calcium, and magnesium, in this order of priority, and apparently in reasonable amounts except perhaps for $\mathrm{NO}_{3}-\mathrm{N} \quad(7.3$ $\mathrm{mg} \cdot \mathrm{L}^{-1}$; Table 1$)$; 2) the quantities of $\mathrm{SO}_{4}$, chlorine, and sodium were sufficiently low to allow for some buildup of these secondary salts (nutrients) and EC in a closed system (Zekki et al., 1996).

During the study, the EC in the two LCM solutions remained within $0.1 \mathrm{EC}$ units of the control solution (Table 1). However, there was $20 \%$ less total nitrogen in the two LCM treatments versus the control. Although a high (5:1) $\mathrm{NO}_{3}: \mathrm{NH}_{4}$ nitrogen ratio is often suggested for optimal plant growth (Barber and Plerzynski, 1991; Kopsell et al., 2007), some species may prefer, or be adaptable to, low ratios (Argo and Biernbaum, 1997; Strojny, 1999). Michitsch et al. (2008) showed that when fertilized with anaerobic digestate wastewaters, three turfgrass species responded positively to $\mathrm{NO}_{3}: \mathrm{NH}_{4}$ ratios $(\approx 1: 9)$. These references, together with results of the present study, indicate that, under our present recirculating cultural conditions, the three test species were adaptable to the very low $\mathrm{NO}_{3}: \mathrm{NH}_{4}$ ratio of the cattle liquid manure solutions (calculated, 0.08 in uLCM and 0.24 in aLCM; Table 1). Even with $50 \mathrm{mg} \cdot \mathrm{L}^{-1}$ of $\mathrm{NO}_{3}-\mathrm{N}$ amendment to the aLCM solution, mean levels of $\mathrm{NO}_{3}-\mathrm{N}$ analyzed over six dates showed no more than $20 \mathrm{mg} \cdot \mathrm{L}^{-1}$ of this nutrient (Table 1 ). This evidence may be indicative of nitrogen loss resulting from denitrification and volatil- ization to $\mathrm{N}_{2}$ or $\mathrm{N}_{2} \mathrm{O}$ gases from the LCM treatments [D. Speranzini, Nutrient Management Program Lead (Hort) and C. Kessel, Horticulture Crop Nutrition-Program lead, Ontario Ministry of Agriculture and Rural Affairs, Guelph, personal communication] and accounting for the similarity in the nitrogen composition of the two LCM treatments.

Not withstanding what has been described previously, plants showed accelerated growth in the three fertigated solutions attaining marketable size within 10 weeks. Better growth in the two LCM solutions versus control may be the result of the presence of growth-stimulating substances in the LCM (Atiyeh et al., 2001) and/or the regressive effect of the greater accumulation of chlorine in the control solution (Table 1) (Gils et al., 2005). Poorer growth responses with CRF (Fig. 1) seemed to be related to lesser uptake of macronutrients, in particular nitrogen, phosphorus, and potassium (Table 2). Data for foliar analysis of the three species indicate lower contents of most foliar nutrients in dogwood compared with cotoneaster and forsythia, except copper and boron (Table 2). Provincial recommendations by the Ontario Ministry of Agriculture, Food and Rural Affairs (OMAFRA, 2003) suggest adequate sufficiency ranges of all foliar nutrients, except zinc and copper. It is also worth noting that no visual sign of nutrient toxicity or deficiency was observed in any of the plants in this experiment or in a similar one conducted the previous year using the same LCM source and test species.

Results of this study demonstrated that liquid cattle manure can be used effectively

Table 2. Foliar nutrient contents of three container-grown species in response to control nutrient solution, unamended liquid cattle manure (uLCM), $50 \mathrm{mg} \cdot \mathrm{L}^{-1}$ $\mathrm{NO}_{3}-\mathrm{N}$ amended liquid cattle manure (aLCM), and controlled-release fertilizer (CRF) treatments.

\begin{tabular}{|c|c|c|c|c|c|c|c|c|c|c|c|}
\hline \multirow[b]{2}{*}{ Treatments } & & Nitrogen & Phosphorus & Potassium & Calcium & Magnesium & Iron & Manganese & Zinc & Copper & Boron \\
\hline & & \multicolumn{5}{|c|}{$(\%)$} & \multicolumn{5}{|c|}{$\left(\mathrm{mg} \cdot \mathrm{L}^{-1}\right)$} \\
\hline Main plot & & $* *$ & $* *$ & $* *$ & $* *$ & $* *$ & $* *$ & $* *$ & $* *$ & $*$ & $*$ \\
\hline \multirow[t]{4}{*}{ Fertilizer $(\mathrm{F})$} & Control & $2.82 A^{\mathrm{z}}$ & $0.31 \mathrm{~A}$ & $2.42 \mathrm{~A}$ & $1.13 B$ & $0.34 B$ & $61 B$ & $44 C$ & $19 D$ & $1.65 B$ & $44 \mathrm{~A}$ \\
\hline & uLCM & $2.30 B C$ & $0.37 A$ & $2.17 B$ & $1.11 B C$ & $0.36 B$ & $105 B$ & $68 B$ & $26 B$ & $2.85 A$ & $46 \mathrm{~A}$ \\
\hline & aLCM & $2.40 B$ & $0.33 B$ & $2.05 B$ & $1.06 C$ & $0.43 A$ & $64 B$ & $58 B C$ & $22 C$ & $2.08 B$ & $45 \mathrm{~A}$ \\
\hline & $\mathrm{CRF}$ & $2.21 C$ & $0.26 C$ & $1.42 C$ & $1.40 \mathrm{~A}$ & $0.41 A$ & $169 A$ & $131 A$ & $32 A$ & $2.73 \mathrm{~A}$ & $40 \mathrm{~B}$ \\
\hline \multicolumn{12}{|l|}{ Subplot } \\
\hline Species (S) & & $* *$ & $* *$ & $* *$ & $* *$ & $* *$ & $*$ & $* *$ & $* *$ & NS & $* *$ \\
\hline Cotoneaster & & $3.03 a$ & $0.30 \mathrm{~b}$ & $1.68 \mathrm{~b}$ & $1.17 b$ & $0.34 b$ & $116 a$ & $66 b$ & $27 a$ & 2.04 & $53 a$ \\
\hline Dogwood & & $2.05 c$ & $0.38 a$ & $2.67 a$ & $1.83 a$ & $0.55 a$ & $63 b$ & $25 c$ & $18 b$ & 2.63 & $53 a$ \\
\hline Forsythia & & $2.22 b$ & $0.27 c$ & $1.69 b$ & $0.52 c$ & $0.26 c$ & $121 a$ & $134 a$ & $29 a$ & 2.31 & $26 b$ \\
\hline \multicolumn{12}{|l|}{ Interaction } \\
\hline $\mathrm{F} \times \mathrm{S}$ & & NS & $*$ & $* *$ & NS & $* *$ & $*$ & $* *$ & NS & NS & $*$ \\
\hline \multirow[t]{4}{*}{ Cotoneaster } & Control & 2.77 & $0.29 b$ & $1.77 a$ & 1.16 & $0.31 b$ & $92 b$ & $46 b$ & 22 & 1.32 & 51 \\
\hline & $\mathrm{uLCM}$ & 3.05 & $0.35 a$ & $1.74 a$ & 1.12 & $0.33 b$ & $102 b$ & $75 a b$ & 30 & 2.29 & 52 \\
\hline & aLCM & 2.85 & $0.30 \mathrm{~b}$ & $1.65 a$ & 1.07 & $0.37 a$ & $80 b$ & $55 a b$ & 23 & 2.26 & 54 \\
\hline & $\mathrm{CRF}$ & 3.46 & $0.28 b$ & $1.58 a$ & 1.36 & $0.35 a b$ & $192 a$ & $88 a$ & 34 & 2.30 & 53 \\
\hline \multirow[t]{4}{*}{ Dogwood } & Control & 1.91 & $0.37 b$ & $3.67 a$ & 1.77 & $0.50 c$ & $47 a$ & $19 a$ & 14 & 2.34 & $57 a$ \\
\hline & uLCM & 1.98 & $0.45 a$ & $3.01 b$ & 1.77 & $0.52 b c$ & $95 a$ & $27 a$ & 18 & 3.50 & $58 a$ \\
\hline & aLCM & 1.90 & $0.41 a$ & $3.64 c$ & 1.66 & $0.63 a$ & $54 a$ & $23 a$ & 17 & 2.22 & $55 a$ \\
\hline & $\mathrm{CRF}$ & 2.40 & $0.29 c$ & $1.38 d$ & 2.13 & $0.54 b$ & 56 & $32 a$ & 25 & 2.46 & $41 b$ \\
\hline \multirow[t]{4}{*}{ Forsythia } & Control & 1.96 & $0.27 a$ & $1.82 a$ & 0.47 & $0.22 c$ & $46 b$ & $66 b$ & 22 & 1.30 & $23 a$ \\
\hline & uLCM & 2.18 & $0.32 a$ & $1.78 a$ & 0.43 & $0.22 c$ & $119 b$ & $101 b$ & 32 & 2.76 & $27 a$ \\
\hline & aLCM & 2.17 & $0.28 a$ & $1.87 a$ & 0.44 & $0.28 b$ & $58 b$ & $95 b$ & 27 & 1.76 & $26 a$ \\
\hline & $\mathrm{CRF}$ & 2.60 & $0.21 b$ & $1.31 b$ & 0.73 & $0.33 a$ & $259 a$ & $273 a$ & 36 & 3.42 & $26 a$ \\
\hline
\end{tabular}

**, *Significant at $P \leq 0.01$ and $P \leq 0.05$, respectively; Ns, nonsignificant.

${ }^{\mathrm{z}}$ Means accompanied by common letters are not significantly different (main plot effects, $A-D$; subplot and interaction effects, $a-c$ ) at $P \leq 0.05$ by least significant difference test. 
as the sole source of nutrients for growing deciduous container nursery plants in a closed-loop nutrient recirculating system. As diluted and used in this study, the liquid manure showed no sign of adverse effects on the plants. This research provides new knowledge on an alternative and innovative option for recycling this type of liquid waste. Recycling liquid cattle manure can eliminate costs for fertilizer and for traditional disposal, creating environmental benefits.

\section{Literature Cited}

Alam, M.Z. and C. Chong. 2006. Recycling compost wastewaters and nutrients in container ornamental production. Recent Res. Develop. Agron. Hort. 2:39-69.

Argo, W.R. and J.A. Biernbaum. 1997. Lime, water source, and fertilizer nitrogen form affect medium $\mathrm{pH}$ and nitrogen accumulation and uptake. HortScience 32:71-74.

Atiyeh, R.M., C.A. Edwards, S. Subler, and J.D. Metzer. 2001. Pig manure vermicompost as a component of a horticultural bedding plant medium: Effects on physiochemical properties and plant growth. Bioresour. Technol. 78:11-20.

Barber, K.L. and G.M. Plerzynski. 1991. Ammonium and nitrate source effects on field crops. J. Fert. Issues. 8:57-62.

Beeson, R.C., Jr., M.A. Arnold, T.E. Bilderback, B. Bolusky, S. Chandler, H.M. Gramling, J.D. LeaCox, J.R. Harris, P.J. Klinger, H.M. Mathers, J.M. Ruter, and T.H. Yeager. 2004. Strategic vision of container nursery irrigation in the next ten years. J. Environ. Hort. 22:113-115.

Beltrao, P., C. Gamito, A. Guerrero, J. Arsenio, and C. Brito. 1999. Grass response to municipal wastewater reuse as compared to nitrogen and water application, p. 263-265. In: Anac, D. and P. Martin-Prevel (eds.). Improved crop quality by nutrient management. Kluwer Academic Publishers, Baltimore, MD.

Chong, C., G. Lumis, P. Purvis, and A. Dale. 2004. Growth and nutrient status of six species of nursery stock grown in a compost-based medium with recycled nutrients. HortScience 39: 60-64.

Chong, C., P. Purvis, G. Lumis, B.E. Holbein, R.P. Voroney, H. Zhou, H.W. Liu, and M.Z. Alam. 2008. Using mushroom farm and anaerobic digestion wastewaters as supplemental fertilizer sources for growing container nursery stock in a closed system. Bioresour. Technol. 99:2050-2060.
Climate Control Systems. 2000. Fertigation manager user manual version 6.31 and 6.51. Climate Control Systems, Leamington, Ontario, Canada.

Gils, J., C. Chong, and G. Lumis. 2005. Response of container-grown ninebark to crude and nutrient-enriched recirculating compost leachates. HortScience 40:1507-1512.

Harrison, D.S. 1976. Irrigation water applied to three commercial container nurseries. Proc. of the Florida State Horticultural Society 90:306-308.

Hong, C.X., J.D. Lea-Cox, D.S. Ross, G.W. Moorman, P.A. Richardson, S.R. Ghimire, and P. Kong. 2009. Containment basin water quality fluctuation and implications for crop health management. Irrig. Sci. 27:485-496.

Kızıloglu, F.M., M. Turan, U. Sahın, I. Angın, O. Anapal1, and M. Okuroglu. 2007. Effects of wastewater irrigation on soil and cabbage-plant (Brassica olerecea var. Capitate cv. Yalova-1) chemical properties. J. Plant Nutr. Soil Sci. 170: 166-172.

Kopsell, D.A., D.E. Kopsell, and J. Curran-Celentano. 2007. Carotenoid pigments in kale are influenced by nitrogen concentration and form. J. Sci. Food Agr. 87:900-907.

Lea-Cox, J.D., D.S. Ross, and K.M. Teffeau. 2004. Developing water and nutrient management plans for container nursery and greenhouse production systems. Acta Hort. 633:373-379.

Little, C.M. and A.A. Grant. 2002. Making integrated anaerobic digestion projects a reality. Biocycle 43:64-68.

Manios, T., I. Papagrigoriou, G. Daskalakis, I. Sabathianakis, S. Terzakis, K. Maniadakis, and G. Markakis. 2006. Evaluation of primary and secondary treated and disinfected wastewater irrigation of tomato and cucumber plants under greenhouse conditions, regarding growth and safety considerations. Water Environ. Res. 78:797-804.

Michitsch, R., C. Chong, B. Holbein, R.P. Voroney, and H.W. Liu. 2008. Fertigation of cool season turfgrass species with anaerobic digestive wastewater. Floricul. Ornamentl. Biotech. 2: 32-38.

Million, J., T. Yeager, and C. Larsen. 2007. Water use and fertilizer response of azalea using several no-leach irrigation methods. HortTechnology 17:21-25.

Moore, M.T., D.L. Denton, C.M. Cooper, J. Wrysinski, J.L. Miller, K. Reece, D. Crane, and P. Robins. 2008. Mitigation assessment of vegetated drainage ditches for collecting irrigation runoff in California. J. Environ. Qual. 37:486-494.
Mosley, L.M. and N. Fleming. 2009. Reductions in water use following rehabilitation of a floodirrigated area on the Murray River in South Australia. Agr. Water Mgt. 96:1679-1682.

OMAFRA (Ontario Ministry of Agriculture, Food and Rural Affairs). 2003. Nursery and landscape plant production and IPM. Publ. 383. Queen's Printer of Ontario, Toronto, Canada.

Owen, J.S., Jr., S.L. Warren, T.E. Bilderback, and J.P. Albano. 2008. Phosphorus rate, leaching fraction, and substrate influence on influent quality, effluent nutrient content, and response of a containerized woody ornamental crop. HortScience 43:906-912.

Papadopoulos, A.P. and N. Liburdi. 1989. The Harrow Fertigation Manager-A computer controlled multifertigation injector. Acta Hort. 260:255-265.

Purvis, P., C. Chong, and G.P. Lumis. 1998. A new computer-controlled multifertilizer injector for recycling nutrients and water runoff in nurseries. Proc. Intl. Plant Prop. Soc. 48:444- 446.

Purvis, P., C. Chong, and G.P. Lumis. 2000. Recirculation of nutrients in container nursery production. Can. J. Plant Sci. 80:39-45.

Qian, Y.L., J.M. Fu, J. Klett, and S.E. Newman. 2005. Effects of long-term recycled wastewater irrigation on visual quality and ion concentration of ponderosa pine. J. Environ. Hort. 23:185-189.

Shrive, S.C., R.A. McBride, and A.M. Gordon. 1994. Photosynthetic and growth responses of two broad-leaf tree species to irrigation with municipal landfill leachate. J. Environ. Qual. 23:534-542.

Skimina, C.A. 1986. Recycling irrigation runoff on container ornamentals. HortScience 21:32-34.

Strojny, Z. 1999. Effect of nutrient solution concentration and $\mathrm{NH}_{4}: \mathrm{NO}_{3}$ ratio on maranta growth. Scientia Hort. 80:105-112.

Wang, J.W., G. Wang, and H. Wanyan. 2007. Treated wastewater irrigation effect on soil, crop and environment: Wastewater recycling in the Loess area of China. J. Environ. Sci. (China) 19:1093-1099.

Welke, S.E. 2004. The effect of compost extract on the yield of strawberries and the severity of Botyrtis cinerea. J. Sust. Agril. 25:57-68.

Yeager, T., R. Wright, D. Fare, C. Gilliam, J. Johnson, T. Bilderback, and R. Zondag. 1993. Six state survey of container nursery nitrate nitrogen runoff. J. Environ. Hort. 11:206-208.

Zekki, H., L. Gauthier, and A. Gosselin. 1996. Growth productivity and mineral composition of hydroponically cultivated greenhouse tomatoes, with or without nutrient solution recycling. J. Amer. Soc. Hort. Sci. 12:1082-1088. 